\title{
BRONCHIAL BIOPSY IN CHRONIC BRONCHITIS AND ASTHMA
}

\author{
BY \\ A. A. GLYNN AND L. MICHAELS \\ From the Wright-Fleming Institute of Microbiology, St. Mary's Hospital Medical School and St. Mary's \\ Hospital, and the Department of Pathology, St. Mary's Hospital Medical School, London
}

(RECEIVED FOR PUBliCATION OCTOBER 24, 1959)

Chronic bronchitis is responsible for a greater annual mortality in Great Britain than any other single respiratory disease, and its incidence is far higher in this country than anywhere else in the world (Oswald, 1958), yet relatively few comprehensive studies of the pathogenesis of the condition have been published.

Considerable attention has been paid recently to the factor of infection in chronic bronchitis, especially with regard to the role of Haemophilus influenzae, since Mulder's work in 1938 (Mulder, 1956 ; May, 1958). Brumfitt, Willoughby, and Bromley (1957) have emphasized the preponderance of $\boldsymbol{H}$. influenzae over other organisms when swabs are taken directly from the bronchi in cases of chronic bronchitis. One of us (A. A. G.) has found antibodies to $H$. influenzae in high titre in two-thirds of patients with the disease. The titres were not significantly affected by intercurrent attacks of acute bronchitis.

It has long been recognized clinically that symptoms of chronic bronchitis may persist in the absence of infection, and clinicians have also for many years been aware that a fundamental characteristic of chronic bronchitis is the excessive production of mucus in the respiratory tract. That infection may thereby be facilitated, and that the association of infection and excess mucus production may ultimately cause emphysema, has been suggested by Reid (1954). Evidence of a histological basis for excess mucus production is as yet lacking, and there are few studies of the detailed pathology of chronic bronchitis as distinct from that of emphysema.

Rokitansky in 1838 described six cases of chronic bronchitis in which grossly dilated mucous glands were present in the posterior wall of the trachea and in the bronchi. This condition is now recognized as an occasional radiological (Simon and Galbraith, 1953) and pathological (Duprez and Mampuys, 1953) manifestation of chronic bronchitis. Rokitansky also described less severe degrees of this mucous glandular dilatation in some of his cases. Huter and Koessler (1922) gave a very detailed account of the pathology of "bronchial asthma" based on six patients of their own and 15 culled from the literature. It is clear from their description that an infective element was present in many. Bronchitis was definite or probable in 12 of the 13 in whom they describe mucous gland hypertrophy, while only in one patient with bronchitis was there mucous gland atrophy. Florey, Carleton, and Wells (1932) mentioned that histological examination of the bronchi in a group of 14 patients with chronic bronchitis showed dilated deep glands, the majority of which were mucous in type. Reid, on the basis of post-mortem studies, stated that mucous gland hypertrophy and goblet cell hyperplasia are early changes in chronic bronchitis, and she has stressed the importance of this view in subsequent papers (Reid, 1958). In general, however, the pathological basis of chronic bronchitis is referred to merely in terms of the name as a chronic inflammation of the bronchial wall.

We report here the results of a study of bronchial biopsies in 45 patients. They fell clinically into two main groups: those with chronic bronchitis ( 27 cases) and those with asthma (18 cases). A more detailed classification is given below.

From these biopsies from living patients we hoped to establish and describe specific histological changes in chronic bronchitis and in asthma, and to determine if possible their relationship to the severity and to the duration of these disorders. Secondly, in patients with clinical evidence of both asthma and bronchitis we hoped that histological evidence might throw light upon the interrelationship of these two disorders.

\section{Material AND Methods}

Bronchoscopy was carried out on 45 patients who were admitted to St. Mary's Hospital for investigation 
and treatment between August, 1957, and January, 1959.

Classification of Patients.-The patients were divided on clinical grounds into 27 with chronic bronchitis and 18 with asthma.

The diagnosis of chronic bronchitis was based on a history of productive cough for at least two years, associated with periodic febrile exacerbations, particularly in winter. Eight patients had pure chronic bronchitis, 10 had started with pure bronchitis but after a number of years had developed wheezing dyspnoea, and nine had wheezed from the onset of bronchitis. The asthmatics all suffered from paroxysmal attacks of wheezing dyspnoea, often with prolonged wheezing between attacks.

Evidence of an allergic basis for the asthma (clear clinical history of sensitivity and at least one of the following: family history of allergy, skin tests, or eosinophilia) was present in eight patients. The aetiology of the asthma in the remaining 10 is unknown.

In six, including four of the allergic patients, infection had become superimposed on the asthma.

The diagnosis is discussed in more detail in relation to the pathological findings.

The patients were graded as mild, moderate, or severe (1-3) by clinical assessment of their functional state. Those in grade 1 (13 cases) suffered little incapacity, those in grade 3 (11 cases) were frequently in hospital or in bed at home and unable to do their normal work. The remainder (21 cases) were put in grade 2 .

BRONCHOSCOPY.-Patients were bronchoscoped in the ward after premedication with omnopon and scopolamine and under local anaesthesia with "lignocaine." Usually no difficulties were encountered and most patients were not distressed though some needed further sedation. There was one death (Case 22) in a patient with severe bronchopneumonia whose bronchi were obstructed by secretions. Secretions were sucked out and the appearance of the mucosa observed. A snippet of mucosa was taken, always from the right middle lobe carina, using Brock's forceps. Only a small amount of capillary bleeding of short duration was produced.

Histological Methods.-The fragment of bronchial mucosa was fixed in formol saline, embedded in paraffin, and cut through its entire thickness at 5 microns, all sections being mounted. In all cases sections were stained by the following methods: haematoxylin and eosin, Van Gieson's stain, Verhoeff's stain for elastic, mucicarmine, alcian blue, periodicacid-Schiff, Gram's and methylene blue stains for bacteria, and toluidine blue for gamma metachromasia. In five cases of asthma and of chronic bronchitis sections were stained for reticulin by Foote's method and by the phloxine tartrazine method for inclusion bodies.

In one case of chronic bronchitis the material was fixed in cold acetone and sections were stained for alkaline phosphatase by Gomori's method and for non-specific esterase by the method of Nachlas and
Seligman (1949). Sections from all cases were examined with the oil immersion (1/12 in.) objective as well as by the usual magnifications.

A record of the main histological features in each case was made without knowledge of the clinical diagnosis.

Sections were also cut of the right middle lobe carina from necropsy specimens of 15 normal lungs, stained by the same methods and used as controls in assessing variations seen in the biopsy material.

\section{RESULTS}

Bronchoscopic Appearances. - A variable amount of mucus or mucopus was seen in the bronchi during bronchoscopy, but its presence, nature, and quantity bore inconstant relationships to the clinical diagnosis. In general, however, in patients presenting primarily with asthma the mucosa of the trachea and bronchi was seen on bronchoscopy to be smooth and moist. In some chronic bronchitics the mucosa was extremely soft and thick so that it bulged over the edge of the bronchoscope. We do not feel, however, that any definite relationship can be established between the naked-eye bronchoscopic appearances and the clinical diagnosis.

Normal Histology of The Bronchus.-The normal bronchial epithelium consists of a surface layer mainly of ciliated cells with occasional goblet cells, an intermediate, and a basal cell layer (Fig. 1). The basement membrane on which the epithelium rests is composed of reticulin and collagen fibres and varies from about 4 to 7

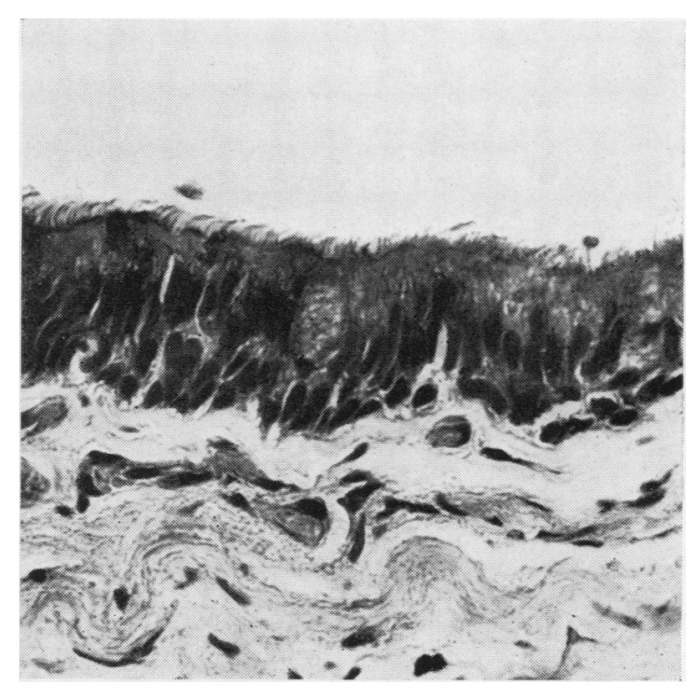

FIG. 1.-Normal bronchial epithelium. Note surface, intermediate and basal layers and cilia arising from surface cells. Haematoxylin and eosin $\times 830$. 
microns in thickness. The normal lamina propria usually shows some degree of lymphocytic infiltration; its deeper part consists of elastic fibres which rest on the smooth muscle layer. Beneath the smooth muscle lie the deep bronchial glands.

Two types of glandular acini may be distinguished, mucous and serous. The latter are normally more frequent, the mucous acini often being few and scattered. The serous acini are characterized by the presence of minute granules which fill the cytoplasm. In most serous acini these granules are basophilic and P.A.S. positive, but in occasional acini the granules are eosinophilic and do not stain with P.A.S. In the mucous acini there are usually some serous cells arranged in demilunes. The cytoplasm of the mucous cells consists of large, irregular, weakly-basophilic globules ; it stains strongly with P.A.S. and mucicarmine. Flat, elongated myo-epithelial cells adhere to the periphery of both mucous and serous glandular acini (Figs. 2 and 3). Ducts lined by goblet cells pass through the smooth muscle layer, lamina propria, and epithelium to open on the surface. Peripheral to the deep bronchial glands is the bronchial cartilage.

Histological Changes in Biopsies of Cilia.Cilia were carefully examined, but we found no constant qualitative alteration nor anything characteristic of bronchitis. In some, cilia were absent as a result of loss of the superficial and inter-

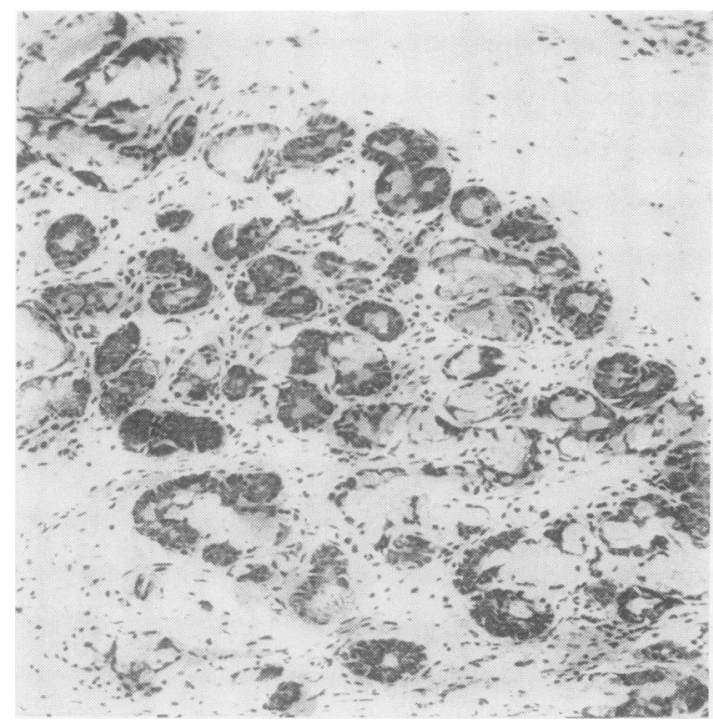

FIG. 2.-Normal bronchial glands in bronchial biopsy of a case of asthma. There are numerous serous acini which stain more deeply than the mucous acini. Haematoxylin and eosin $\times 104$.

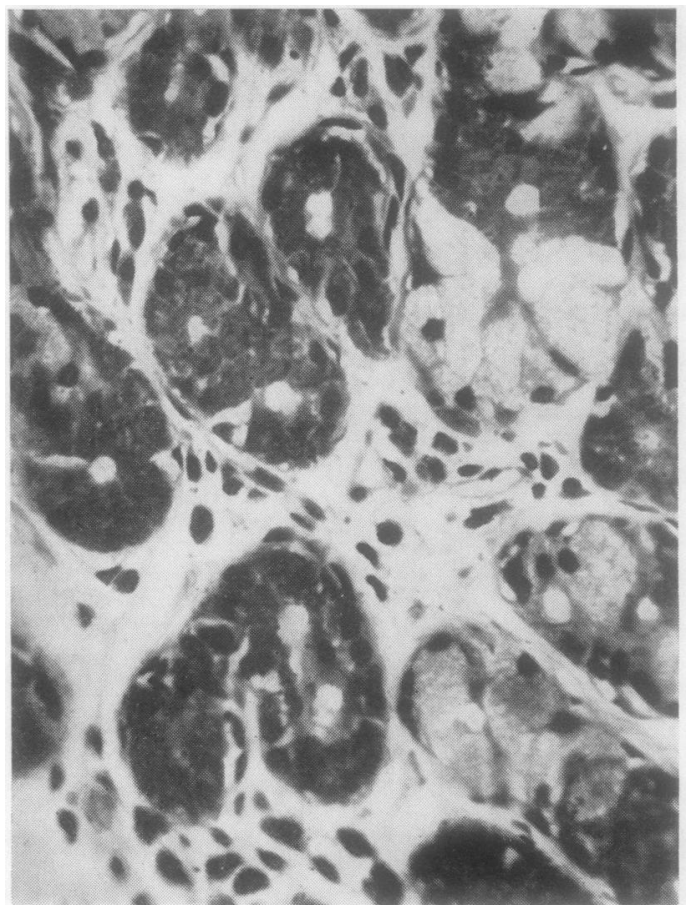

Fig. 3.-High-power view of part of Fig. 2. The serous cells contain numerous dark granules in their cytoplasm. These are eosinophils and plasma cells between the glands. Haematoxylin and eosin $\times 830$.

mediary layers of the epithelium, a loss which was probably an artefact and due to the trauma of the operation. Sometimes, however, although the whole thickness of the epithelium was intact, cilia were deficient or absent. This finding was usually associated with severe goblet cell hyperplasia, yet cilia were sometimes seen arising from surface goblet cells.

SQuamoid Metaplasia.-Squamoid metaplasia was found in seven patients, six of whom had asthma, the other chronic bronchitis. The change was not uniform throughout the epithelium in any, and the remainder of the epithelium was of normal columnar secretory type.

Typical "prickle cells" were not seen, so that the term squamous metaplasia cannot be applied ; but in some cases intercellular connexions were present and perhaps represented early "pricklecell" formation. Keratinization was not seen. In P.A.S.- or mucicarmine-stained sections mucoid secretion was sometimes seen in the cytoplasm of the surface cells in squamoid areas; it was not visible in haematoxylin and eosin sections (Figs. 4 and 5). Mitoses were occasionally present in cell nuclei in the squamoid areas of epithelium. 


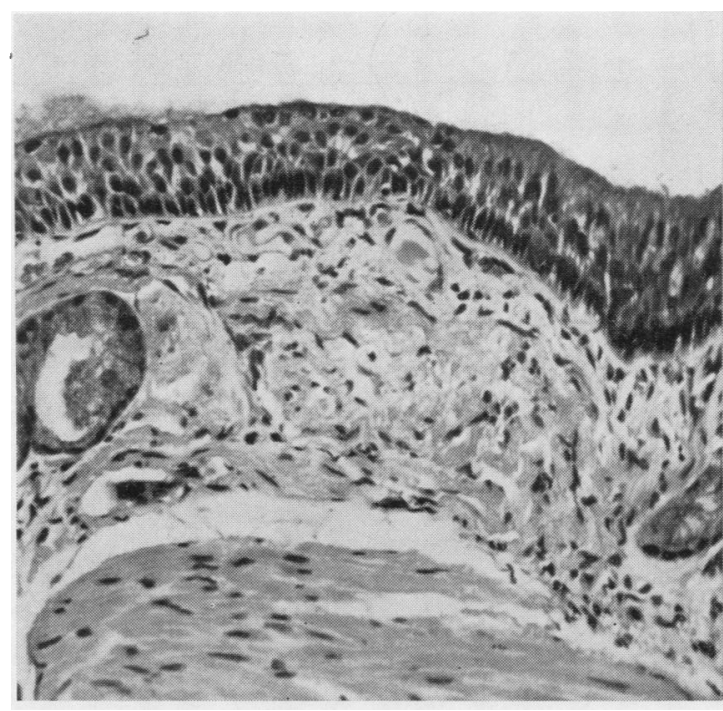

FIG. 4.-Bronchial biopsy from a case of asthma. The epithelium shows squamoid change on the left and is of the normal ciliated variety on the right. Haematoxylin and eosin $\times 400$.

Goblet Cell Hyperplasia.-A considerable increase in mucus-containing goblet cells in the surface epithelium was observed frequently in this series. This feature is shown in Tables I-III as + , denoting that a majority of the surface cells

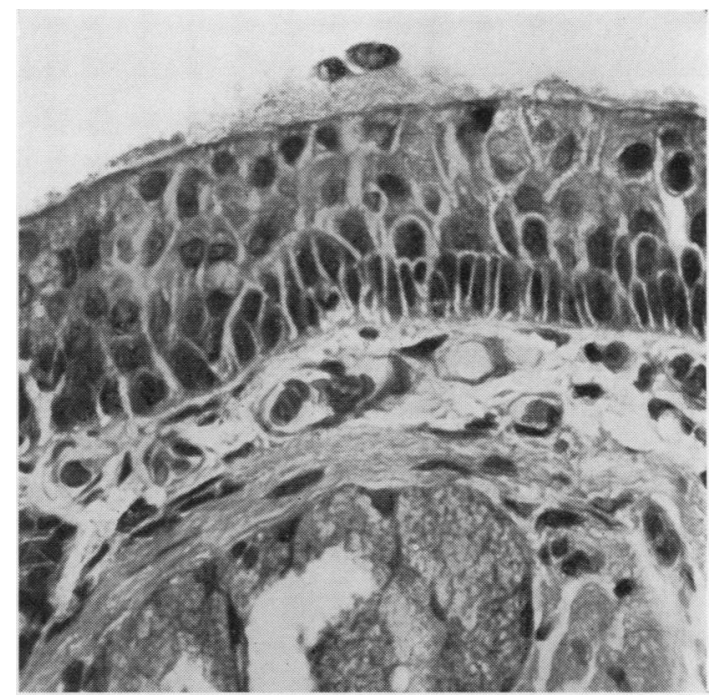

FIG. 5.-High-power view of part of squamoid area of Fig. 4. The epithelial cells are flattened towards the surface. Haematoxylin and eosin $\times 830$.

are goblet cells, and as ++ when all surface cells are goblet cells. The sign \pm indicates that an occasional surface cell is a goblet cell, compatible with the appearance in the normal bronchus (Fig. 6).

TABLE I

PATHOLOGICAL AND CLINICAL FEATURES IN CASES WITH MUCOUS CHANGE IN GLANDS (GROUP 1)

\begin{tabular}{|c|c|c|c|c|c|c|c|c|c|c|}
\hline $\begin{array}{l}\text { Case } \\
\text { No. }\end{array}$ & $\begin{array}{l}\text { Deep } \\
\text { Glands }\end{array}$ & $\begin{array}{c}\text { Eosinophils } \\
\text { in Lamina } \\
\text { Propria }\end{array}$ & $\begin{array}{l}\text { Goblet } \\
\text { Cells }\end{array}$ & Diagnosis & $\underset{\text { (Years) }}{\text { Age }}$ & Sex & $\begin{array}{l}\text { Length of } \\
\text { History } \\
\text { (Years) }\end{array}$ & $\begin{array}{c}\text { Clinical } \\
\text { Grade }\end{array}$ & $\begin{array}{c}\text { H. influenzae } \\
\text { in } \\
\text { Sputum }\end{array}$ & Tobacco \\
\hline $\begin{array}{l}14 \\
17 \\
12 \\
44\end{array}$ & $\begin{array}{c}\mathbf{M}+++ \\
,, \\
,,\end{array}$ & $\begin{array}{l} \pm \\
\pm \\
\pm \\
\pm \\
\pm\end{array}$ & $\begin{array}{c}+ \\
++ \\
+ \\
++\end{array}$ & $\begin{array}{c}\mathbf{B} \\
\mathbf{B} \\
\mathbf{B}+\mathbf{A} \\
\mathbf{B} \rightarrow \mathbf{B}+\mathbf{A}\end{array}$ & $\begin{array}{l}54 \\
58 \\
66 \\
53\end{array}$ & $\begin{array}{l}\mathbf{F} \\
\mathbf{F} \\
\mathbf{F} \\
\mathbf{M}\end{array}$ & $\begin{array}{l}30 \\
20 \\
40 \\
45\end{array}$ & $\begin{array}{l}2 \\
2 \\
3 \\
3\end{array}$ & $\begin{array}{l}+ \\
+ \\
+ \\
+\end{array}$ & $\begin{array}{l}0 \\
0 \\
0 \\
0\end{array}$ \\
\hline $\begin{array}{l}26 \\
19 \\
27 \\
31 \\
34 \\
22 \\
29\end{array}$ & $\begin{array}{c}\text { M++ } \\
,, \\
,, \\
, " \\
,,\end{array}$ & $\begin{array}{l}0 \\
0 \\
\pm \\
\pm \\
+ \\
\pm \\
\pm \\
\end{array}$ & $\begin{array}{l} \pm \\
\pm \\
\pm \\
+ \\
++ \\
+ \\
\pm \\
+\end{array}$ & $\begin{array}{c}\mathbf{B} \\
\mathbf{B}+\mathbf{A} \\
\mathbf{B} \rightarrow \mathbf{B}+\mathbf{A} \\
\mathbf{B} \rightarrow \mathbf{B}+\mathbf{A} \\
\mathbf{A} \rightarrow \mathbf{A}+\mathbf{B} \\
\mathbf{A}^{\mathbf{2}} \\
\mathbf{A}^{\mathbf{3}}\end{array}$ & $\begin{array}{l}57 \\
54 \\
60 \\
53 \\
26 \\
57 \\
57\end{array}$ & $\begin{array}{l}\mathbf{M} \\
\mathbf{M} \\
\mathbf{M} \\
\mathbf{M} \\
\mathbf{M} \\
\mathbf{F} \\
\mathbf{M}\end{array}$ & $\begin{array}{r}16 \\
12 \\
18 \\
17 \\
9 \\
10 \\
1\end{array}$ & $\begin{array}{l}2 \\
3 \\
3 \\
2 \\
2 \\
2 \\
2\end{array}$ & $\begin{array}{l}+ \\
0^{1} \\
+ \\
+ \\
+ \\
0 \\
0\end{array}$ & $\begin{array}{l}+ \\
+ \\
+ \\
0 \\
0 \\
0 \\
+\end{array}$ \\
\hline $\begin{array}{l}13 \\
11 \\
16 \\
20 \\
39 \\
36 \\
25\end{array}$ & $\begin{array}{c}\mathbf{M}+ \\
,, \\
,, \\
, ", \\
,,\end{array}$ & $\begin{array}{l} \pm \\
\pm \\
+ \\
+ \\
0 \\
\pm \\
\pm\end{array}$ & $\begin{array}{c}++ \\
\pm \\
++ \\
\pm \\
\pm \\
++ \\
+\end{array}$ & $\begin{array}{c}\mathbf{B} \\
\mathbf{B}+\mathbf{A} \\
\mathbf{B}+\mathbf{A} \\
\mathbf{B}+\mathbf{A} \\
\mathbf{B}+\mathbf{A} \\
\mathbf{B} \rightarrow \mathbf{B}+\mathbf{A} \\
\mathbf{A}\end{array}$ & $\begin{array}{l}65 \\
58 \\
66 \\
64 \\
46 \\
58 \\
30\end{array}$ & $\begin{array}{l}\mathbf{M} \\
\mathbf{M} \\
\mathbf{F} \\
\mathrm{F} \\
\mathrm{F} \\
\mathbf{M} \\
\mathbf{M}\end{array}$ & $\begin{array}{r}3 \\
6 \\
4 \\
12 \\
16 \\
3 \\
8\end{array}$ & $\begin{array}{l}2 \\
2 \\
1 \\
2 \\
2 \\
2 \\
2\end{array}$ & $\begin{array}{l}+ \\
0 \\
+ \\
0 \\
0 \\
+ \\
0\end{array}$ & $\begin{array}{l}+ \\
\pm \\
- \\
0 \\
0 \\
+ \\
+\end{array}$ \\
\hline
\end{tabular}

1 Acute infection treated with antibiotics before admission. 2 Plus pneumococcal bronchopneumonia. 3 Plus staphylococcal pneumonia. Mucous change in deep glands: $\mathbf{M}+++=$ All deep acini mucous. No serous acini. No demilunes. $\mathbf{M}++=\mathbf{D e e p}$ glands predominantly mucous. Occasional serous acini. Occasional demilunes. $\mathbf{M}+=$ Increase of mucous glands. Numerous serous acini and demilunes. $\mathbf{M} \pm=$ Small numbers of mucous glands only in section. $\mathbf{S}=$ Serous glands predominant. No mucous gland increase. $\mathbf{S} \pm=\mathbf{S m a l l}$ number of serous glands only in section. $-=$ No glands in section.

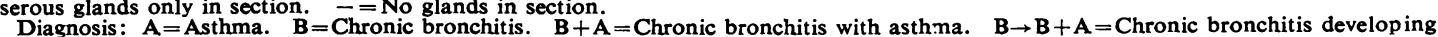
asthma later. $A \rightarrow A+B=$ Asthma developing bronchitis later.

Goblet cells: $++=$ All surface cells are goblet cells. $\quad+=$ Most surface cells are goblet cells. $\quad \pm=$ Occasional surface cells are goblet cells. - = Surface epithelium absent.

Eosinophils in lamina propria: $+=$ Numerous. $\pm=$ Occasional. $0=$ Absent. 
TABLE II

PATHOLOGICAL AND CLINICAL FEATURES IN CASES WITH PREDOMINANTLY SEROUS GLANDS (GROUP 2)

\begin{tabular}{|c|c|c|c|c|c|c|c|c|c|c|}
\hline $\begin{array}{l}\text { Case } \\
\text { No. }\end{array}$ & $\begin{array}{c}\text { Deep } \\
\text { Glands }\end{array}$ & $\begin{array}{c}\text { Eosinophils } \\
\text { in Lamina } \\
\text { Propria }\end{array}$ & $\begin{array}{c}\text { Goblet } \\
\text { Cells }\end{array}$ & Diagnosis & $\begin{array}{c}\text { Age } \\
\text { (Years) }\end{array}$ & Sex & $\begin{array}{l}\text { Length of } \\
\text { History } \\
\text { (Years) }\end{array}$ & $\begin{array}{l}\text { Clinical } \\
\text { Grade }\end{array}$ & $\begin{array}{c}H . \text { influenzae } \\
\text { in } \\
\text { Sputum }\end{array}$ & Tobacco \\
\hline $\begin{array}{r}3 \\
4 \\
7 \\
33 \\
35 \\
37 \\
43 \\
1 \\
2 \\
10 \\
18 \\
24 \\
9 \\
21 \\
6 \\
38 \\
41 \\
42\end{array}$ & $\begin{array}{c}\text { Serous } \\
\text {,, } \\
\text {,, } \\
\text {,, } \\
\text {,, } \\
\text {,, } \\
\text {,, } \\
\text {,, } \\
\text {,, } \\
\text {,, } \\
\text {,, }\end{array}$ & $\begin{array}{l}+ \\
+ \\
+ \\
+ \\
+ \\
+ \\
+ \\
+ \\
+ \\
+ \\
+ \\
+ \\
+ \\
+ \\
+ \\
0 \\
+ \\
+\end{array}$ & $\begin{array}{l}\overline{-} \\
\pm \\
\pm \\
++ \\
\pm \\
+ \\
- \\
++ \\
+ \\
+ \\
\pm \\
+ \\
+ \\
\pm \\
+ \\
++\end{array}$ & $\begin{aligned} & \mathbf{A} \\
& \mathbf{A} \\
& \mathbf{A} \\
& \mathbf{A} \\
& \mathbf{A} \\
& \mathbf{A} \\
& \mathbf{A} \\
& \mathbf{A} \rightarrow \mathbf{A}+\mathbf{B} \\
& \mathbf{A} \rightarrow \mathbf{A}+\mathbf{B} \\
& \mathbf{A} \rightarrow \mathbf{A}+\mathbf{B} \\
& \mathbf{A} \rightarrow \mathbf{A}+\mathbf{B} \\
& \mathbf{A} \rightarrow \mathbf{A}+\mathbf{B} \\
& \mathbf{B}+\mathbf{A} \\
& \mathbf{B} \rightarrow \mathbf{B}+\mathbf{A} \\
& \mathbf{B} \rightarrow \mathbf{B}+\mathbf{A} \\
& \mathbf{B} \rightarrow \mathbf{B}+\mathbf{A} \\
& \mathbf{B} \\
& \mathbf{B}\end{aligned}$ & $\begin{array}{l}65 \\
43 \\
55 \\
52 \\
16 \\
52 \\
34 \\
49 \\
60 \\
47 \\
55 \\
47 \\
60 \\
53 \\
67 \\
49 \\
66 \\
61\end{array}$ & $\begin{array}{l}\mathbf{F} \\
\mathbf{F} \\
\mathbf{M} \\
\mathbf{F} \\
\mathbf{F} \\
\mathrm{F} \\
\mathbf{F} \\
\mathbf{F} \\
\mathrm{F} \\
\mathbf{F} \\
\mathbf{F} \\
\mathbf{F} \\
\mathbf{F} \\
\mathbf{F} \\
\mathbf{F} \\
\mathbf{F} \\
\mathbf{F} \\
\mathbf{M}\end{array}$ & $\begin{array}{r}6 \\
20 \\
4 \\
11 \\
8 \\
25 \\
4 \\
7 \\
20 \\
6 \\
3 \\
18 \\
1 \\
13 \\
3 \\
4 \\
9 \\
2\end{array}$ & $\begin{array}{l}3 \\
1 \\
3 \\
2 \\
1 \\
2 \\
1 \\
1 \\
2 \\
1 \\
2 \\
1 \\
2 \\
2 \\
1 \\
1 \\
3 \\
1\end{array}$ & $\begin{array}{c}0 \\
+ \\
0 \\
0 \\
0 \\
0 \\
0 \\
+ \\
0 \\
0 \\
+ \\
0 \\
+ \\
0 \\
0 \\
0 \\
0 \\
+\end{array}$ & $\begin{array}{c}0 \\
- \\
0 \\
0 \\
0 \\
0 \\
+ \\
- \\
0 \\
- \\
0 \\
0 \\
0 \\
0 \\
+ \\
0 \\
0\end{array}$ \\
\hline
\end{tabular}

Mucous change in deep glands: $\mathbf{M}+++=$ All deep acini mucous. No serous acini. No demilunes. $\mathbf{M}++=$ Deep glands predominantly mucous. Occasional serous acini. Occasional demilunes. $\mathbf{M}+=$ Increase of mucous glands. Numerous serous acini and demilunes. $\mathbf{M} \pm=$ Small numbers of mucous glands only in section. $\mathbf{S}=$ Serous glands predominant. No mucous gland increase. $\mathbf{S} \pm=$ Small number of serous glands only in section. $-=$ No glands in section.

Diagnosis: $\mathbf{A}=$ Asthma. $\mathbf{B}=$ Chronic bronchitis. $\mathbf{B}+\mathbf{A}=$ Chronic bronchitis with asthma. $\mathbf{B} \rightarrow \mathbf{B}+\mathbf{A}=\mathbf{C h r o n i c}$ bronchitis developing asthma later. $\mathbf{A} \rightarrow \mathbf{A}+\mathbf{B}=$ Asthma developing bronchit is later.

Goblet cells: $++=$ All surface cells are goblet cells. $+=$ Most surface cells are goblet cells. $==$ Occasional surface cells are goblet cells - = Surface epithelium absent.

Eosinophils in lamina propria: $t=$ Numerous. $\pm=$ Occasional. $0=$ Absent.

TABLE III

PATHOLOGICAL AND CLINICAL FEATURES IN CASES WITH FEW OR NO GLANDS IN SECTION (GROUP 3)

\begin{tabular}{|c|c|c|c|c|c|c|c|c|c|c|}
\hline $\begin{array}{l}\text { Case } \\
\text { No. }\end{array}$ & $\begin{array}{c}\text { Deep } \\
\text { Glands }\end{array}$ & $\begin{array}{l}\text { Eosinophils } \\
\text { in Lamina } \\
\text { Propria }\end{array}$ & $\begin{array}{l}\text { Goblet } \\
\text { Cells }\end{array}$ & Diagnosis & $\begin{array}{c}\text { Age } \\
\text { (Years) }\end{array}$ & Sex & $\begin{array}{l}\text { Length of } \\
\text { History } \\
\text { (Years) }\end{array}$ & $\begin{array}{c}\text { Clinical } \\
\text { Grade }\end{array}$ & $\begin{array}{c}\text { H. influenzae } \\
\text { in } \\
\text { Sputum }\end{array}$ & Tobacco \\
\hline $\begin{array}{r}15 \\
30 \\
40 \\
5 \\
8 \\
23 \\
32 \\
28 \\
45\end{array}$ & $\begin{array}{l}\mathbf{M} \\
\mathbf{M} \\
\mathbf{M} \\
\mathbf{S}_{ \pm} \\
\mathbf{S} \\
\mathbf{S}_{ \pm} \\
\mathbf{S} \pm \\
-\end{array}$ & $\begin{array}{l}0 \\
0 \\
\vdots \\
+ \\
\pm \\
+ \\
+ \\
+ \\
+ \\
0 \\
0\end{array}$ & $\begin{array}{l}+ \\
+ \\
+ \\
++ \\
- \\
++ \\
\pm+ \\
++\end{array}$ & $\begin{array}{c}\mathbf{B}+\mathbf{A} \\
\mathbf{B} \rightarrow \mathbf{B}+\mathbf{A} \\
\mathbf{B} \\
\mathbf{B} \rightarrow \mathbf{B}+\mathbf{A} \\
\underset{\mathbf{A}}{\mathbf{A}} \\
\mathbf{B}+\mathbf{A} \\
\mathbf{B} \rightarrow \mathbf{B}+\mathbf{A} \\
\mathbf{B}\end{array}$ & $\begin{array}{l}46 \\
43 \\
65 \\
49 \\
38 \\
57 \\
34 \\
45 \\
44\end{array}$ & $\begin{array}{l}\mathbf{M} \\
\mathbf{F} \\
\mathbf{M} \\
\mathbf{M} \\
\mathbf{M} \\
\mathbf{F} \\
\mathrm{F} \\
\mathbf{M} \\
\mathbf{M}\end{array}$ & $\begin{array}{r}4 \\
17 \\
20 \\
40 \\
7 \\
6 \\
4 \\
20 \\
3\end{array}$ & $\begin{array}{l}3 \\
2 \\
3 \\
3 \\
2 \\
1 \\
1 \\
3 \\
1\end{array}$ & $\begin{array}{l}+ \\
+ \\
+ \\
+ \\
+ \\
0 \\
0 \\
0 \\
+ \\
+\end{array}$ & $\begin{array}{l}0 \\
0 \\
+ \\
+ \\
0 \\
+ \\
0 \\
0 \\
+ \\
0\end{array}$ \\
\hline
\end{tabular}

Mucous change in deep glands: $\mathbf{M}+++=$ All deep acini mucous. No serous acini. No demilunes. $\mathbf{M}++=$ Deep glands predominantly mucous. Occasional serous acini. Occasional demilunes. $\mathbf{M}+=$ Increase of mucous glands. Numerous serous acini and demilunes. $\mathbf{M} \pm=$ Small numbers of mucous glands only in section. $\mathbf{S}=$ Serous glands predominant. No mucous gland increase. $\mathbf{S}=\mathbf{S}$ mall number of serous glands only in section. $-=$ No glands in section.

Diagnosis: $\mathbf{A}=\mathbf{A}$ - Asthma. $\mathbf{B}=$ Chronic bronchitis. $\mathbf{B}+\mathbf{A}-$ Chronic bronchitis with asthma. $\mathbf{B} \rightarrow \mathbf{B}+\mathbf{A}=$ Chronic bronchitis developing asthma later. $\quad A \rightarrow A+B=$ Asthma developing bronchitis later

Goblet cells : $++=$ All surface cells are goblet cells. $+=$ Most surface cells are goblet cells. $+=$ Occasional surface cells are goblet cells. $=$ Surface epithelium absent.

Eosinophils in lamina propria: $t=$ Numerous. $t=$ Occasional. $0=$ Absent

BACTERIA.-Bacteria, including bacilli resembling $H$. influenzae, were not seen in the epithelium on examination of Gram- or methylene-blue-stained sections, despite repeated search.

Basement Membrane.-Measurements were made of the thickness of basement membrane in Van-Gieson-stained sections using an eyepiece micrometer. Care was taken to make measurements in portions of basement membrane subjacent to vertically cut epithelium.

Abnormalities noted were: (1) thinning, (2) reduplication, and (3) thickening.
(1) Thinning of basement membrane was seen in 10 cases. It was always associated with severe inflammatory congestion of the lamina propria, with numerous congested capillaries in contact with the outer surface of the basement membrane giving an appearance suggesting absorption of the latter by encroachment of capillaries on it (Fig. 7). This change was found in cases of both asthma and chronic bronchitis.

(2) Reduplication occurred in two patients with asthma in whom the basement membrane consisted of numerous collagenous layers each of which 


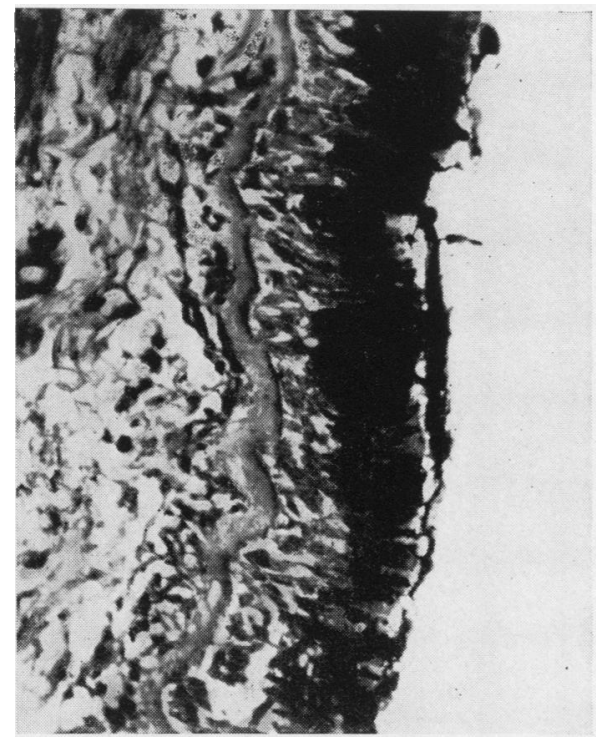

Fig. 6.-Bronchial epithelium from biopsy of a case of asthma. There is a layer of mucus on the surface, appearing black in the photograph but red in the original. Goblet cells are increased in number and constitute most of the surface cells. Note the basement membrane beneath the epithelium. Periodic-acidSchiff $\times \mathbf{4 0 0}$.

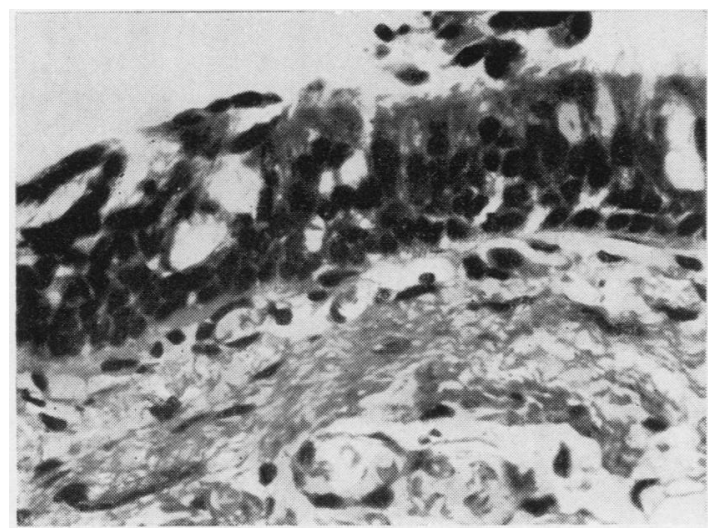

FIG. 7.-Bronchial biopsy from a case of asthma showing thinning of the basement membrane. Note the inflammatory congestion and exudate encroaching on basement membrane. Haematoxylin and van Gieson $\times 830$.

was thinner than normal basement membrane. Fibroblasts were present between the layers of collagen (Fig. 8).

(3) A definitely thickened basement membrane of 9 to $10 \mu$ in width was seen in only three patients, two with asthma and one with bronchitis (Fig. 9).

Lamina Propria.-A degree of leucocytic infiltration was present in the lamina propria in every

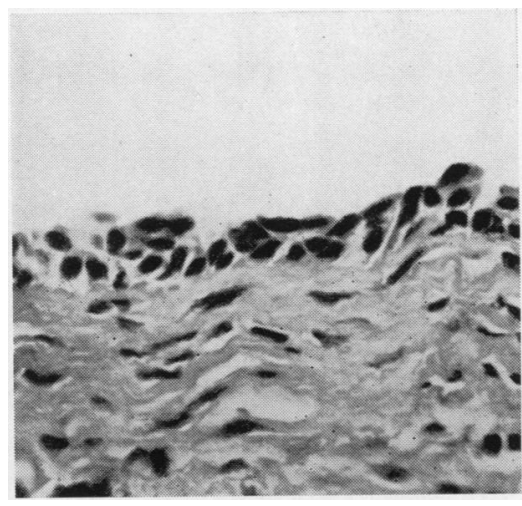

Fig. 8.-Bronchial biopsy from a case of asthma showing reduplication of the basement membrane. Instead of a single homogeneous layer the basement membrane now consists of numerous layers of collagen separated by fibroblasts. Haematoxylin and van Gieson $\times 830$.

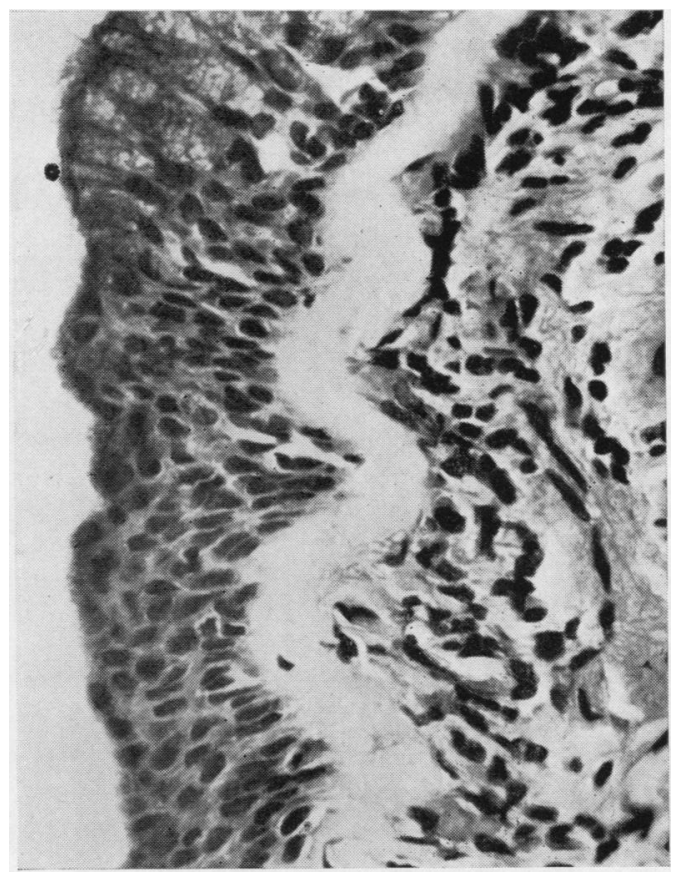

Fig. 9.-Bronchial biopsy from a case of asthma showing thickening of the basement membrane (about $11 \mu$ ) which is here represented by an unstained zone between epithelium and lamina propria. Haematoxylin and eosin $\times 830$.

case, but the extent of the observed infiltration was unrelated to infection or to the severity of the clinical condition. In asthma, the exudate usually consisted predominantly of eosinophil and plasma cells. The former did not need special staining, being readily recognized in haematoxylin and eosin-stained sections, using an oil immersion 
objective, by their large pink granules. The eosinophil cells were sometimes disintegrated, and were then represented only by numerous free granules in some areas. Eosinophil cells were commonly found within the lumina of capillaries as well as in the connective tissue. Occasionally they were seen straddled across the basement membrane; they were also often present in moderate numbers within the epithelium and around the deep glands. They were always accompanied by a variable, often heavy, infiltrate of plasma cells. Seven of the cases showing heavy eosinophilia of the lamina propria were under treatment with prednisone when the bronchial biopsy was taken. In chronic bronchitis the exudate was variable in extent and type, and large numbers of polymorphs, plasma cells, lymphocytes, and macrophages with an occasional eosinophil were usually found.

Variation was also found in the thickness of the elastic layer of the lamina propria. It was in no way characteristic either of asthma or of bronchitis.

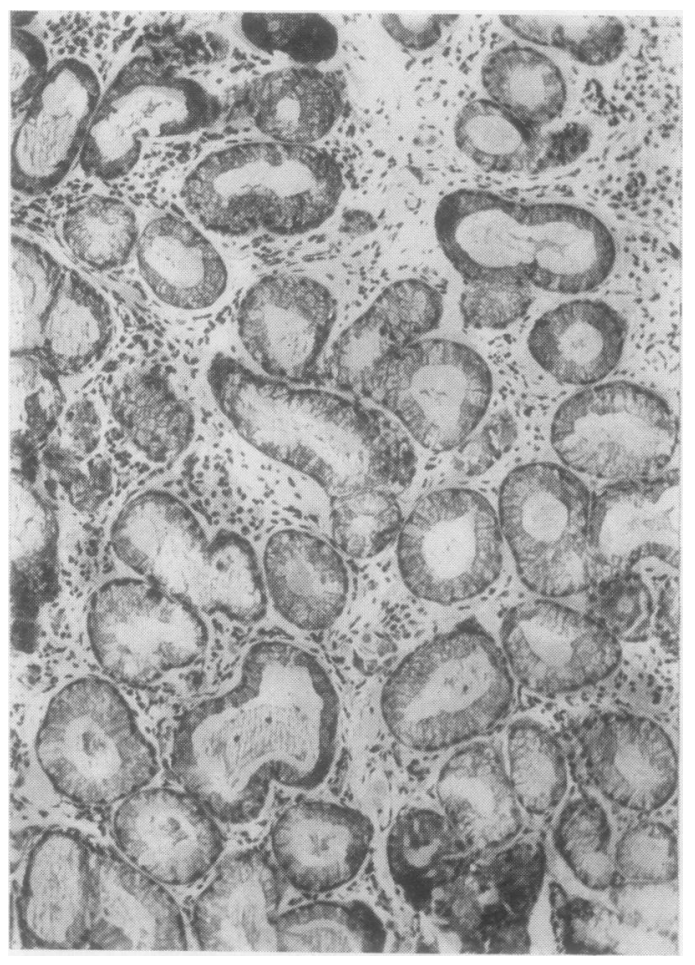

FIG. 10.-Deep bronchial glands from biopsy of a case of severe chronic bronchitis (30-year history) showing severe mucous change $(+++)$. The acini are all mucous in type and are larger than normal. Magnification and staining are the same as in Fig. 2.

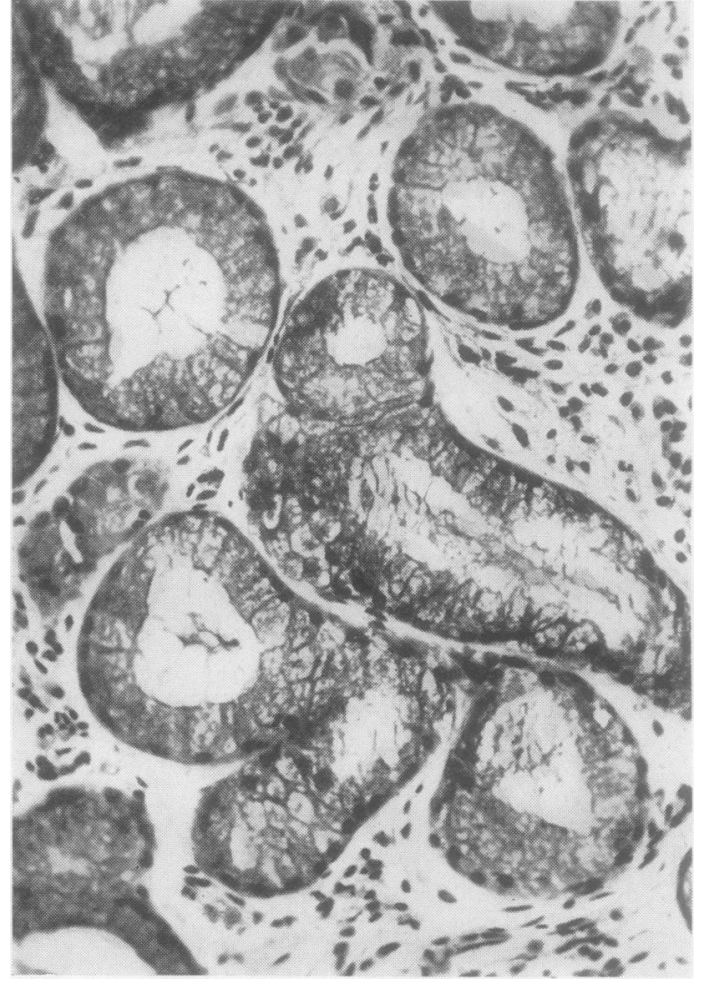

FIG. 11.-High-power view of part of Fig. 4. There is a leucocytic infiltration between the glandular acini. Haematoxylin and $\operatorname{eosin} \times \mathbf{4 0 0}$.

MUSCLE.-The smooth muscle layer, compared with normal controls, was not modified in bronchitis or in asthma.

GLaNDS.-In most biopsies a considerable amount of deep glandular tissue was present.

Marked changes were found in the deep glands in most chronic bronchitics in this series. These changes consisted of a variable degree of replacement of the normally predominant serous glands by hypertrophied mucous glands. The following description applies to all cases in this study found to have severe mucous gland hypertrophy and designated in the tables as +++ or ++ . Serous glands were greatly reduced in number or absent ; if present their morphology was normal, being usually of the basophilic variety, though in some cases a few eosinophilic granular acini were present. Demilunes were absent. Only an occasional glandular acinus in any field showed evidence of active mucus discharge; the appearances are then of small flat cells enclosing a lumen filled with mucus. Most of the mucous acini showed overdistension of the cytoplasm with 
mucus rather than its excessive discharge into the lumen. The mucous acini were greater in diameter than normal, their component cells taller and somewhat wider, and had cytoplasm stained in a less basophilic fashion than in normal bronchi. Mitoses were not seen (Figs. 10 and 11).

Differences were not found between the staining properties of normal and hypertrophied mucous glands. A strong reaction with P.A.S. and mucicarmine and gamma metachromasia with toluidine blue was shown by the cytoplasm of the mucous glands; this latter reaction is often seen in the mucous glands found in the normal bronchus and it cannot be taken to denote any chemical change in the mucous secretion in cases of chronic bronchitis. Inclusion bodies were not seen in phloxine-tartrazine-stained sections. No esterase was found in the biopsy from the single case tested in this way. Alkaline phosphatase was present only in its customary situation around blood vessels.

The ducts were often lined by goblet cells showing a more distended, less basophilic mucus content than normal, and in several specimens there was an apparent increase in ducts central to the muscle layer, with glandular acini, including serous glands, arising from the ducts in this abnormal situation (Fig. 12).

Lesser degrees of mucous change in the deep glands are designated as + in the tables.

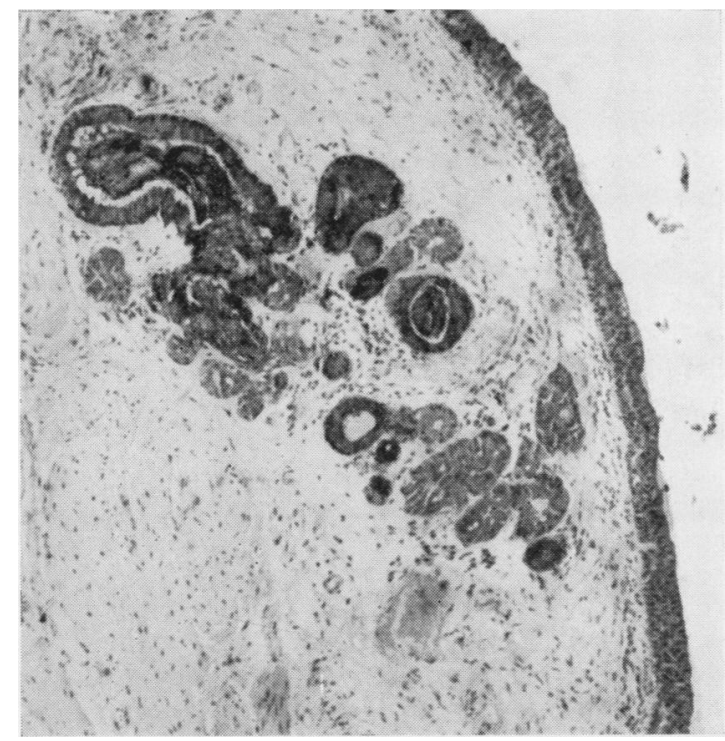

FIG. 12.-Bronchial biopsy from cases of long-standing chronic bronchitis. Small acini, some of them serous in type, are arising from ducts in the lamina propria. Haematoxylin and mucicarmine $\times 140$.
Correlation of Clinical with Pathological FINDINGS. - The clinical diagnoses, made independently of the histological appearances, are complicated, ranging from patients with pure bronchitis through those with varying degrees of bronchitis and asthma to those with pure asthma. We have therefore tabulated our results on the basis of the major histological finding-mucous change in the deep glands-into three groups. Group 1 consists of 18 patients with mucous change in the bronchial glands, group 2 of 18 patients with predominantly serous glands, and group 3 of nine patients in whom too few glands were present in the sections for them to be properly classified. The clinical features and the other histological findings in the three groups are presented in Tables I to III and discussed more fully below.

Group 1.-Fourteen of the 18 patients (Table I) in this group had chronic bronchitis. In 10 of these some asthmatic symptoms were also present, but all had well-established cough with purulent or mucopurulent sputum. $H$. influenzae was isolated from the sputum in 10 of the 14 cases.

The remaining four patients were all asthmatics. Case 34 , though primarily suffering from pollen asthma, had had, over the previous 18 months, two severe and prolonged attacks of bronchitis with $H$. influenzae in his sputum. At the time of biopsy Case 22 had a severe pneumococcal bronchopneumonia, and Case 29 a staphylococcal pneumonia with abscess formation. Only in Case 25 , who had asthma with a minor allergic and a major psychogenic element, was there no clinical and bacteriological evidence of infection.

With a few exceptions the degree of mucous change was related to the length of history. Thus all patients with severe mucous change $(+++)$ had a history of 20 years or more of chronic bronchitis. Lesser degrees of the change were associated with a shorter history.

Although it is a little surprising that three of the four with severe mucous change were women, the probability of this occurring by chance is 1 in 23 , given the relatively high proportion of women (seven out of 18) in the whole bronchitis group. This excess of women compared with the numbers found in special bronchitis clinics is almost certainly due to local factors in selection. Many patients were referred via the allergy clinic, and there were more female than male beds available. The reports of Fry (1954), Goodman, Lane, and Rampling (1953), and others show that chronic bronchitis is more common in women than is sometimes supposed. 
The early age of onset ( 8 years) in Case 44 raises the possibility of some inherent abnormality of mucous secretion, but, in the absence of any supporting evidence for this hypothesis and taking the series as a whole, it seems better to regard the marked changes as the result of prolonged disease.

Increased numbers of goblet cells were found in 10 patients, three with bronchitis, five with bronchitis and asthma, and two with asthma alone. All but the two last had $\boldsymbol{H}$. influenzae in their sputum.

Excessive infiltration with eosinophils was found in only four patients with bronchitis, all of whom also had asthmatic symptoms. Three of these (Cases 12, 20, and 34) had an allergic history. Only one (Case 20) had ever had a blood eosinophilia $(1,000 /$ c.mm. $=8 \%)$ though not at the time when the biopsy was taken.

Group 2.-All but two of the 18 cases in this group were predominantly asthmatic. Of the two exceptions one, Case 42, had had mild bronchitis for two years, the other, Case 41, had had severe bronchitis for many years.

Of the asthmatics three (Cases 6, 21, and 38) had started with mild bronchitis, but when seen had had little or no cough and sputum for some years. In none of the three was there evidence of infection. Five more asthmatics had developed, after several years of asthma, mild attacks of acute bronchitis in the 12 to 18 months before being bronchoscoped.

$H$. influenzae was isolated from the sputum in five patients, including one asthmatic with no clinical evidence of infection. Ten patients had large numbers of goblet cells; in seven of these there were symptoms of mild bronchitis.

Eosinophils were numerous in the lamina propria in 17 cases including both the pure bronchitics. Nine of the 17 (Cases 2, 3, 4, 9, 18, $21,24,38$, and 42) at some time had a blood eosinophil count of over $9 \%$.

Group 3.-In two of these no deep glands at all were seen in the sections; in the remainder very few glands were present.

In three patients, all with bronchitis, the few glands present were mucous. In four, two with bronchitis and asthma and two with pure asthma, the glands were serous.

Five patients, four of them with $H$. influenzae in the sputum, had increased numbers of goblet cells.

Three in this group showed an excess of eosinophil infiltration in the lamina propria.

\section{TовАссо}

Smoking was more common (seven out of 16) among the patients having mucous gland excess than in those with serous glands (two out of 14) (Tables I and II).

However, as information about smoking habits was not complete it would be unwise to stress the difference between the two groups. Moreover, Table I shows that there is no relation between smoking and the degree of mucous conversion, which suggests that tobacco is not the immediate cause of mucous change, though it has been shown by Oswald and Medvei (1955) and Palmer (1954) that bronchitis is more frequent among smokers than among non-smokers. The present distribution of smokers may simply be a reflection of the fact that 10 of the 13 were men, among whom both bronchitis and smoking are more common.

Goblet cell hyperplasia was not found significantly more frequently among smokers.

\section{Discussion}

In general the histological pattern in chronic bronchitis would seem to be quite distinct from that in asthma. In chronic bronchitis few or no eosinophils were found in the lamina propria, and the deep glands showed an increase in number and size of mucous acini as compared with normal. In asthma, on the other hand, eosinophils were plentiful in the lamina propria and the deep glands were morphologically normal, with a preponderance of serous glands.

The mucous gland change was the most striking feature in chronic bronchitis. We usually obtained sufficient glandular material to see this change clearly, because the biopsy was taken at the bifurcation of a bronchus, where we had a firm grasp of the whole thickness of the mucosa. Sometimes when the mucosa was seen to be distinctly thickened at bronchoscopy, microscopic examination showed severe "mucous" change, namely, a particularly large number of deep mucous glands.

The pathological features comprising mucous change consisted of an increase both in the number of mucous relative to serous glands, and an increase in size of the mucous acini due to the swelling of their component cells and their lumina. We think it is unlikely that new formation of glandular acini takes place; the change is probably the result of transformation of serous into mucous acini followed by increase in size of the latter. The granules of the majority of serous cells gave similar staining reactions to the cytoplasm of the mucous cells, and interchange from 
one type of cell to the other might be a recurrent process in their normal activity. The terms "mucous" and "serous" as applied to bronchial glands are derived from the morphological similarity that these glands show to salivary gland acini, where each type of acinus has been shown to produce its own distinct form of secretion. No such relationship has ever been shown with regard to the glands in the respiratory tract, and it seems inherently more likely that the two histological varieties represent different grades of activity in the production of mucous secretion. We consider the mucous change, therefore, as being in the nature of a work hypertrophy of the secretory tissue.

Probably the mucous glandular transformation takes place not only at the site examined in our bronchial biopsies but also at all levels of the bronchial tree. We have studied histologically pieces of trachea removed from the anterior tracheal wall at tracheostomy in two chronic bronchitics. Both showed appreciable increase in mucous glands as compared with the normal. In one, a man of 40 with one year's history of bronchitis and a recent bronchopneumonia, the mucous change was of moderate degree (corresponding to between + and ++ ). In the other, a woman of 55 with a history of chronic bronchitis for four years and recent bronchopneumonia, the mucous change in the tracheal glands was more severe (corresponding to between ++ and +++ ). Studies of the bronchial glands in cases of chronic bronchitis coming to necropsy are being carried out by one of us (L. M.) and have already shown in three cases a striking degree of mucous glandular change $(+++)$ in all parts of the trachea and bronchial tree, the deep glands presenting a far greater volume of tissue than normal.

We have obtained histological material from each patient on a single occasion only, so that we cannot state whether the mucous change is permanent or reversible. We think that some with mild mucous change do revert to normal, but in severe chronic bronchitis, in view of the persistence of symptoms, the mucous change is permanent.

The diagnosis of chronic bronchitis has hitherto only been possible on clinical grounds by a process of exclusion of other respiratory or cardiovascular diseases in a patient with a chronic cough (Scadding, 1959). The evidence we present here suggests that the mucous change in the deep glands may represent the pathological basis of chronic bronchitis, which correlates well with the clinical view that an increased production of mucoid sputum is a basic feature of the disease (Oswald,
1958). The pathological changes vary in degree according to the severity of the disease, which may often be measured by the length of history, since most patients become progressively worse with passage of time. In four of our patients with very long histories of chronic cough, a maximum degree of mucous change was present. Lesser degrees of this change are not specific and may be produced by relatively acute respiratory infections, since they were seen not only in chronic bronchitis of shorter duration but also in two patients with asthma in whom bronchopneumonia had developed at the time when the biopsy was taken (Table I, Cases 22 and 29). Because of this clear relationship of the glandular changes to the severity of the disease, we feel that bronchial biopsy in which glandular tissue is included may prove to be a valuable aid in the diagnosis and prognosis of chronic bronchitis as well as in the scientific study of the disease. The functional grading as defined above of the cases of chronic bronchitis shows less relationship to the degree of mucous change than does the length of history, but it should be remembered that such a grading is a very rough assessment of the severity of the disease and is probably an index more of the degree of coexistent emphysema than of chronic bronchitis.

Increase in surface goblet cells was seen in many cases in this series. This feature was described by Reid (1954) as an early change in chronic bronchitis. The tables show that many cases of asthma as well as chronic bronchitis have moderate $(+)$ or marked $(++)$ increase of goblet cells. Engel (1958) suggests that increase in goblet cells may simply be a manifestation of mild irritation to the bronchus. Since infection may be an important type of irritant producing this change, we have tabulated (Table IV) the incidence of infection in patients with and without goblet cell hyperplasia. The positive association between goblet cell hyperplasia and $\boldsymbol{H}$. influenzae infection

TABLE IV

RELATIONSHIP OF GOBLET CELL HYPERPLASIA TO INFECTION

\begin{tabular}{l|c|c|c}
\hline & $\begin{array}{c}\text { Total } \\
\text { Cases }\end{array}$ & $\begin{array}{c}\text { No. of } \\
\text { Cases with } \\
\text { H.influenzae } \\
\text { Isolated } \\
\text { from Sputum }\end{array}$ & $\begin{array}{c}\text { No. of } \\
\text { Cases with } \\
\text { Pneumococci } \\
\text { Isolated } \\
\text { from Sputum }\end{array}$ \\
\hline $\begin{array}{c}\text { Normal numbers of gob- } \\
\text { let cells (N) }\end{array}$ & 11 & 2 & 4 \\
$\begin{array}{c}\text { Goblet cells increased } \\
\text { (+ or + +) }+ \text { orium in }\end{array}$ & 27 & 17 & 9 \\
$\begin{array}{c}\text { No surface epithelium } \\
\text { section }\end{array}$ & 7 & 3 & 4 \\
\hline
\end{tabular}

Cf. goblet cell hyperplasia in patients with and without $H$. influenzae infection $x^{2}=6.2$. $n=1, P=0<0.02$.

Cf. goblet cell hyperplasia in patients with and without pneumococcal infection $\chi^{2}=0.02, \mathrm{n}=1, \mathrm{P}=0>0.9$. 
is significant at the $2 \%$ level, but the distribution of pneumococci could easily have occurred by chance. Brumfitt et al. (1957) have stressed that not all organisms found in the sputum arise from the bronchi. Pneumococci are frequently contaminants from the throat. In the present series the pneumococci were found in the throat or nose of eight of the 17 patients with pneumococci in the sputum. In only four cases did the course of illness and the response to antibiotics suggest that pneumococci were playing a significant part. The goblet cells were increased in two of these. However, although in this series infection with $H$. influenzae appears to have been important in the production of goblet cell hyperplasia, it is clear from Table IV that other factors must also sometimes operate.

We found eosinophils were numerous in the lamina propria in most asthmatics, and this feature was more nearly constant than the presence of a blood eosinophilia or of numerous eosinophils in the sputum. Numerous eosinophils were occasionally seen in the lamina propria of our chronic bronchitics, but these usually had asthmatic symptoms as well, and it is possible that there was an added allergic factor in these cases. Two with symptoms of bronchitis only (Cases 41 and 42, Table II) had a heavy eosinophil infiltrate and no mucous change in the bronchial glands. A condition of "allergic eosinophilic bronchitis" has been described by Mulder (1956) in which patients with symptoms of bronchitis and not asthma have numerous eosinophils in their sputum. Cases 41 and 42 would seem to fit into this category.

The presence of a local eosinophilia in the seven cases in which therapy with prednisone was in progress when the biopsy was taken is of interest. The blood esosinophils are as a rule considerably reduced in such patients, suggesting that the eosinophils seen may have migrated from the blood or have been produced locally in the bronchial wall. Numerous eosinophils are commonly seen in the lumina of capillaries in the lamina propria of asthmatics, and it is possible that the new formation of eosinophils takes place close to the capillary walls. This may explain the persistence of eosinophils in the sputum after they have disappeared from the blood under the influence of steroid therapy.

Thickening of the basement membrane beneath the bronchial epithelium is described as a constant feature in bronchial asthma (Cardell, 1956), but was seen in only two of the 18 patients with asthma in the present series. In most reports available to us on the state of the basement membrane in asthma it has been described as thickened on the basis of a study of random sections usually of small bronchi included with lung material. With few exceptions no attempt has been made in the published reports to standardize the site at which the membrane was observed or to attempt measurements in vertically cut areas. Our measurements on biopsy material at a standard site in the bronchial tree suggest that thickening of the basement membrane is not as common in cases of asthma as would be supposed from the literature, which is based mainly on reports of cases of status asthmaticus coming to necropsy. Huber and Koessler (1922) found thickening of all elements of the bronchial wall in their patients with asthma (and bronchitis) compared with bronchi of similar outside diameter from normal controls. However, Kourilsky, Decroix, Blondeau, and Ganter (1952) observed "fibrosis" of the lamina propria in 10 of their 19 cases in which biopsy material from the right middle lobe bronchus was obtained. This appears to be similar to or identical with the reduplication of the basement membrane which we have described in two of our asthmatics. Thickening of the basement membrane was also seen in one chronic bronchitic in our series. This is in keeping with the observations of Crepea and Harman (1955), who have shown that basement membrane thickening is not confined to asthma but may be found in a wide variety of lung diseases.

\section{SUMmary}

Biopsy of the bronchial mucosa at the right middle lobe carina was performed in 45 patients with chronic bronchitis or asthma or a combination of the two.

The bronchitics frequently showed changes in the deep glands, characterized by an increase in size and number of mucous acini and a disappearance of serous cells. The degree of mucous change appeared to be related to the duration of the disease. We suggest that mucous change of the deep glands is the cardinal pathological feature of severe chronic bronchitis. Patients with asthma consistently showed a heavy infiltration of eosinophils into the lamina propria.

Hyperplasia of surface goblet cells was seen in both asthma and chronic bronchitis and was probably related to infection.

Squamoid metaplasia of the epithelium was seen in seven patients, but true squamous change was not. Thinning, reduplication, and thickening of the basement membrane were found. 
We wish to thank Dr. W. D. W. Brooks, Professor D. M. Pryce, and Dr. A. W. Frankland for much encouragement and advice, Mr. L. L. Bromley for instruction in the use of the bronchoscope, Mr. P. Abbey for the provision of the tracheostomy specimens, and Miss G. Latham for invaluable technical assistance.

\section{REFERENCES}

Brumfitt, W., Willoughby, M. L. N., and Bromley, L. L. (1957). Lancet, 2,1306

Cardell, B.'S.'(1956). Int. Arch. Allergy, 9, 189.

Crepea, S. B., and Harman, J. W. (1955). J. Allergy, 26, 453.

Duprez, A., and Mampuys, R. (1953). Thorax, 8, 141 .

Engel, S. (1958). J. clin. Path., 11, 302.

Florey, H.. Carleton, H. M., and Wells, A. Q. (1932). J. exp. Path., 13, 269.
Fry, J. (1954). Brt. med. J., 1, 190.

Goodman, N., Lane, R. E., and Rampling, S. B. (1953). Ibid., 2,237

Huber, H. L., and Koessler, K. K. (1922). Arch. intern. Med., 30, 689.

Kourilsky, R., Decroix, G., Blondeau, M., ana Ganter, Y. (1952) J. franc. Méd. Chir. thor., 6, 201.

May, J. R. (1958). In Recent Trends in Chronic Bronchitis, ed. Oswald, N. C. Lloyd-Luke, London.

Mulder, J. (1938). Acta med. scand., 94, 98.

Nachlas, M. M., and Seligman, A. M. (1949). J. nat. Cancer Inst., 9, 415 .

Oswald, N. C. (1958). Ed. of Recent Trends in Chronic Bronchitis. Lloyd-Luke, London.

and Medvei, V. C. (1955). Lancet, 2, 843.

Palmer, K. N. V. (1954). Brit. med. J., 1, 1473.

Reid, L. McA. (1954). Lancet, 1, 275.

(1958). Postgrad. med. J. 34, 24.

Rokitansky, C. (1838). Ost. Jb., 16, 382.

Scadding, J. G. (1959). Lancet, 1, 323 .

Simon, G., and Galbraith, H.-J. B. (1953). Ibid., 2, 850. 